\title{
Acupuncture In The Real World: Evaluating a 15-Year NADA Auricular Acupuncture Service For Breast Cancer Survivors Experiencing Hot Flushes And Night Sweats As a Consequence of Adjuvant Hormonal Therapies
}

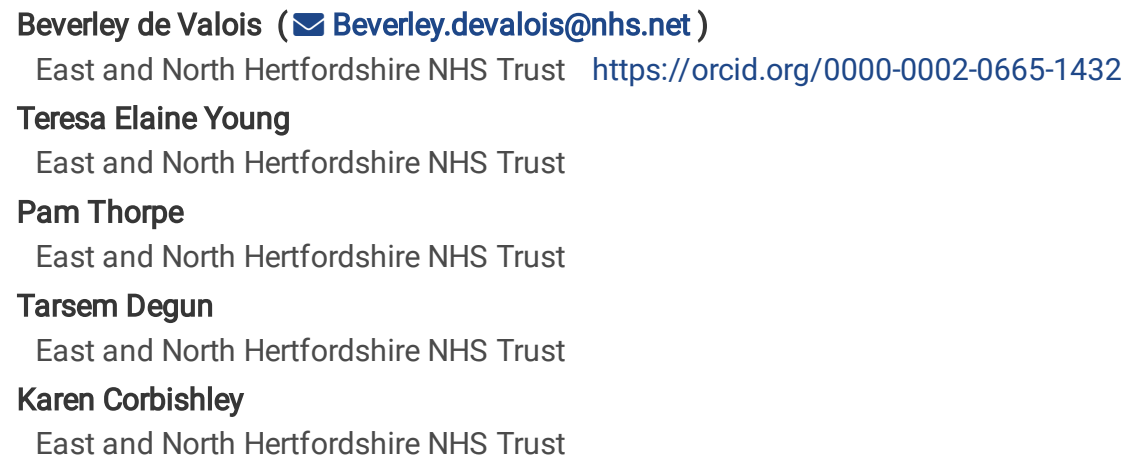

\section{Research Article}

Keywords: Acupuncture (MESH), Auricular acupuncture (MESH), Breast cancer (MESH), Hot flushes (MESH), Cancer Survivors (MESH), Menopause (MESH)

Posted Date: December 28th, 2021

DOI: https://doi.org/10.21203/rs.3.rs-1075043/v1

License: (c) (i) This work is licensed under a Creative Commons Attribution 4.0 International License. Read Full License

Version of Record: A version of this preprint was published at Supportive Care in Cancer on February 26th, 2022. See the published version at https://doi.org/10.1007/s00520-022-06898-7. 


\section{Abstract}

\section{Purpose}

While clinical trials provide valuable data about efficacy of interventions, findings often do not translate into clinical settings. We report real world clinical outcomes of a 15-year service offering breast cancer survivors auricular acupuncture to manage hot flushes and night sweats (HFNS) associated with adjuvant hormonal treatments. This service evaluation aims to 1) assess whether usual practice alleviates symptoms in a clinically meaningful way and 2) compare these results with scientific evidence.

\section{Methods}

Data were analysed from 415 referrals to a service offering women eight standardised treatments using the National Acupuncture Detoxification Association (NADA) protocol. Outcome measures administered at baseline, end of treatment (EOT), and four- and 18- weeks after EOT included Hot Flush Diaries, Hot Flush Rating Scale (HFRS) and Women's Health Questionnaire (WHQ).

\section{Results}

2285 treatments were given to 300 women; 275 (92.3\%) completed all eight treatments. Median daily frequency of HFNS reduced from 9.6 (IQR 7.3) to 5.7 (IQR 5.8) at EOT and 6.3 (IQR 6.5) 18 weeks after EOT. HFRS problem rating showed a clinically meaningful reduction of $\geq 2$ points at all measurement points. WHQ showed improvements in several symptoms associated with the menopause. Two adverse events were reported, neither were serious. Results are comparable to published research.

\section{Conclusion}

This first analysis of a long-term auricular acupuncture service compares favourably with outcomes of other studies for reducing HFNS frequency and associated menopausal symptoms. In day-to-day clinical practice, NADA appears to be a safe effective intervention for breast cancer survivors.

\section{Background}

Hot flushes and night sweats (HFNS) are a consequence of adjuvant hormonal treatments (tamoxifen and aromatase inhibitors) for breast cancer [1], of which there were 55,000 new cases annually in the UK from 2015-2017 [2]. They have been reported by up to 84\% of women taking tamoxifen, with $60 \%$ reporting symptoms as severe [3]. Previous opinion held that these symptoms alleviate with time [4], however recent research reports that prevalence may remain static for the duration of adjuvant hormonal treatment and continue for five years after treatment ends $[3,5]$.

A common symptom of natural menopause, hot flushes are described as sudden sensations of heat, often accompanied by sweating, reddening of the skin, and sometimes by palpitations [6]. They are associated with impaired quality of life, poor sleep and negative mood [7],with night sweats associated with a greater risk of minor depression, fatigue and mood changes [8].

Cancer treatment induced HFNS are reported as more severe, frequent, and longer-lasting than those of natural menopause [1, 9]. HFNS have a wider implication for cancer survival, as treatment side effects are cited as a key reason for low adherence to endocrine therapy, with consequent impact on survival [10].

The main treatment for menopausal symptoms, hormone replacement therapy (HRT), is contraindicated for use with women with breast cancer, as are progestogens $[1,8]$. Non-hormonal pharmacological treatments most likely to be offered for HFNS management include selective serotonin (and norepinephrine) reuptake inhibitors (SSRIs and SNRIs), especially venlafaxine, as well as gabapentin and clonidine. Due to concerns about the inhibitory effects of SSRIs and SRNIs on tamoxifen, paroxetine and fluoxetine are not recommended for women taking tamoxifen [1]. However, some women do not find these products helpful, whilst others find the mild to moderate beneficial effects are outweighed by their adverse effects $[1,5]$. Furthermore, many women do not want to take medications in addition to their adjuvant hormonal therapy and seek non-pharmacological options $[9,11]$.

Acupuncture is a non-pharmacological intervention considered by healthcare professionals and breast cancer survivors alike. A survey of UK healthcare professionals reported $50 \%$ suggested it to breast cancer survivors experiencing HFNS, with over 50\% of those women who used it reporting it as being helpful [5]. As an intervention for managing HFNS, it has been widely researched [12]. In RCTs comparing acupuncture with pharmacological interventions, acupuncture was found to be equally effective as gabapentin [13] and venlafaxine [14], with less rebound effect after the end of active treatment and fewer adverse effects [15]. In addition, acupuncture appears to have beneficial effects on the wider symptoms associated with menopause [16], including sleep problems, anxiety, low mood, poor concentration, as well as improved energy and health related quality of life. In examining longer term benefits, systematic reviews report that the maintenance effect on HFNS and associated 
menopausal symptoms is at least 3 months, suggesting that acupuncture's effects are not short-term or placebo [17, 18]. Furthermore, the reported side effects are minor and are typically bruising or transient pain at the needling site [14, 19-24].

While systematic reviews of acupuncture generally conclude that methodological issues compromise the findings of RCTs, it is also known that the findings of RCTs often do not translate to clinical settings [25]. We evaluated real world clinical outcomes for breast cancer survivors receiving standardised auricular acupuncture, the NADA (National Acupuncture Detoxification Association) protocol [26, 27], for HFNS by evaluating data collected from a 15-year service offered in a hospital outpatient setting. The aims were to:

- provide an insight into whether usual clinical practice can alleviate symptoms to a clinically meaningful extent [28]

- assess whether real world acupuncture data aligns with scientific evidence [29].

In reporting this evaluation, this paper adheres to the Template for Intervention Description and Replication (TIDierR) Checklist [30].

\section{Materials And Methods}

\section{Approval and setting}

The NADA acupuncture service was offered from 2005 to 2020 by the Complementary Therapy Service (CTS) at the Lynda Jackson Macmillan Centre (LJMC), a cancer information and drop-in centre associated with Mount Vernon Cancer Centre in Northwood, Middlesex UK. Data collection to evaluate the service was approved by the LJMC Medical Director in 2005; in line with the Declaration of Helsinki guidelines for unproven interventions in clinical practice, all service users gave written consent to their participation in the evaluation of the service [31]. The CTS was supported by the Centre's research team, who administered and analysed the service data.

UK non-acupuncturists with a healthcare qualification (including integrative practitioners) can become NADA specialists on receiving initial training and annual updates. This service saw four practitioners train as NADA specialists, one of whom was a specialist breast cancer nurse, and the others were integrative therapists practising a range of therapies. Co-authors PT and TD have further developed the service and administered treatments for the last 13 and eight years respectively.

\section{Service description}

This service was built on our previous research using the NADA protocol, which we have reported elsewhere [22, 32]. Briefly, the research and service comprise an intake interview at least two weeks prior to the first NADA treatment, then a course of eight treatments delivered weekly in a group setting to women meeting these criteria: taking adjuvant hormonal treatments for early breast cancer (tamoxifen or aromatase inhibitors) for $\geq 6$ months, post-active cancer treatment (surgery, chemotherapy and/or radiotherapy) completed $\geq 6$ months previously, self-reporting an average of $\geq 4$ HFNS in a 24 -hour period for $\geq 3$ months, and not receiving concurrent complementary therapies. Women were referred by their oncology healthcare professionals or could self-refer.

Once established, the service evolved to fulfil the Centre's ethos of care, adapting in response to the needs of women who were service users rather than research participants. Changes include:

- A sample treatment (needles in one ear for five minutes) was given at the intake interview after the woman gave written consent for treatment and completed baseline measures.

- Increased focus on developing the therapeutic relationship, which had been minimised in the research.

- Therapists offered support when administering the baseline outcome measures, as some women found completing these challenging.

- Groups were limited to four women, rather than five, in response to feedback about the comfort of the small clinical spaces available in the centre.

- A brief group relaxation exercise was introduced. This preceded needling, which took place in the group, rather than individually in a separate room.

Other changes related to data collection. Mid-treatment outcomes were not monitored, reducing the number of measurement points to four, as described below. The NADA specialists administered and collected the outcome measures at baseline. At the eighth and final treatment, they gave the women the end of treatment outcome measures and a stamped addressed envelope, with instructions to complete them that day. These were to be posted with the completed Hot Flush Diary two weeks later to the research team's data administrator, who also administered the outcome measures for the two follow-up points by post. 
Safety and adverse events were formally recorded on incident forms and in patient notes following procedures applied to all complementary therapy services delivered in the LJMC.

\section{Outcome measures}

To monitor the service, we used the same outcome measures as in our research. These were administered at baseline, end of treatment (EOT), and at four (Post tx 4) and 18 (Post tx 18) weeks after EOT. Briefly outlined below, we have described these elsewhere [21, 22]:

- Hot Flush Diaries - to measure HFNS frequency and severity these in-house designed booklets enable women to record frequency and severity of incidents at 2-hourly intervals daily, ideally as they occur, for up to 14 days.

- Hot Flush Rating Scale (HFRS) - to measure the extent to which HFNS are a problem, this validated self-report measure has three questions using 10-point Likert scales to rate the extent to which HFNS are problematic, distressing, and the cause of interference in daily life [33, 34]. Problem rating is calculated as the mean of the three questions, with higher scores indicating more problematic HFNS. A change of 2 points on this scale is considered clinically relevant [35].

- Women's Health Questionnaire (WHQ) - to evaluate quality of life, this validated 36-item questionnaire measures changes in nine domains of physical and emotional health associated with the menopause transition. Analysis according to the WHQ Women's Health Questionnaire User Guide [36] results in a score between $0.00-1.00$, where higher scores are associated with worse symptomology and quality of life. A change of $0.10-0.20$ is clinically meaningful.

\section{Statistics}

Data were analysed using SPSS V22.0. The frequency of HFNS per day for each woman was calculated from data entered onto the hot flush diaries. Provided at least six of the 12 2-hourly intervals were completed on any one day (including "0" for no HFNS) and any missing data appeared to be random, the daily means and medians were calculated from the available data (effectively imputing missing data points with the daily means or medians calculated from the reported data points).

As in our previous HFNS studies, log transformation of these calculated daily means produced a normal distribution, allowing parametric t-tests to be used for comparison with baseline scores [21, 22].

Data from the HFRS and WHQ were assessed for normality. On the WHQ domains Depressed Mood and Memory/Concentration were very skewed, whilst other scales were less skewed but exhibited kurtosis. Only Somatic Symptoms was normally distributed. Data were therefore analysed using both Student's t tests and their non-parametric equivalent. Similar significance levels were achieved with both analyses, so only $\mathrm{t}$ tests are reported here.

\section{Results}

We are interested in both short- and long-term results, and thus we report data from all measurement points.

\section{Enrolment, attendance, and questionnaire return}

Figure 1 displays the course of 415 referrals to the service and the resulting data sets used in this evaluation, including reasons for ineligibility, withdrawal prior to treatment, treatments received and data return.

At least 2285 NADA treatments were given to 300 women, of whom 275 (92.3\%) completed the full course of eight treatments, with a mean of seven treatments per individual. However, questionnaire return at EOT was only $71 \%$, falling to $49 \%$ at 18 weeks post-treatment. Forty percent of the women returned all questionnaires at all time points. There was no significant difference in baseline scores on any of the outcome measures between participants completing only baseline measures and those completing baseline and at least one set of follow-up measures.

\section{Participant demographics and clinical features}

Key features of the baseline characteristics (Table 1) are a predominately white British ethnicity (74\%), the majority of whom were currently taking Tamoxifen (63.7\%) followed by Anastrozole (15.7\%). Nearly $70 \%$ of the women had been receiving adjuvant hormone therapy for six to 24 months.

\section{HFNS frequency}

At baseline, women were experiencing a median of 9.6 (Interquartile range [IQR] 7.3) HFNS per day, reducing to 5.7 (IQR 5.8) at EOT and 6.3 (IQR 6.5) at 18 weeks after EOT (Table 2). 
Analysis revealed that $7 \%$ of women had fewer HFNS than the $\geq 4$ per 24 -hour period stated in the eligibility criteria. HFNS counts were selfreported at the intake interview and could not be verified until the baseline hot flush diary was returned on the day of the first NADA treatment and subsequently analysed. This suggests that women found even low numbers of HFNS problematic enough to warrant having treatment.

At the other end of the spectrum, 10\% recorded 24-36 HFNS per day and one woman reported as many as 94 HFNS in a day. Although this could be considered an outlier, we have included it in the analysis as an example of how extreme HFNS can be.

\section{Hot Flush Rating Scale (HFRS)}

At baseline, women were experiencing a mean problem rating score of 7.56 (SD 1.7) out of 10, reducing to 5.42 (2.55), 4.90 (2.53) and 5.18 (2.56) at EOT, four weeks post EOT and final follow up at 18 weeks. (Table 3).

\section{Women's Health Questionnaire (WHQ)}

Improvements were seen in all but one domain at all time points (Table 3), compared to baseline. These were clinically significant (a change of $\geq 0.1$ ) for anxiety/fears, sleep problems and vasomotor symptoms.

\section{Comparing NADA service outcomes with our previous NADA research}

Comparisons of the outcomes of the service with our previous NADA research are shown in Table 4. Paired ' $t$ ' tests show significant improvements for both service users (SU) and research participants (RP) for HFNS frequency, HFRS and WHQ domains.

Unpaired ' $t$ ' tests show no significant differences between SU and RP with the exception of HFRS, where SU had greater improvements than RP at both follow up points. Additionally, RPs had greater improvements on the WHQ depressed mood domain.

\section{Safety and adverse events}

There were two recorded incidents of adverse reactions. Dizziness experienced at the first treatment caused one woman to immediately discontinue NADA treatment, while another woman attributed dizziness and nausea on initial needling to an existing migraine and continued all further treatments.

Pain at the needle site and bleeding on removal of needles were experienced by some women; these were managed according to NADA protocol, recorded in the patient notes, and are not analysed here. These are all commonly reported as minor adverse events of acupuncture [37].

One incident form recorded a lost needle. The potential for losing needles was diminished when the design of needle handles changed from stainless steel to fluorescent orange plastic, making them easy to locate if they fell out of the ear during treatment.

\section{Discussion}

The aims of this evaluation were to gain insight into whether usual clinical practice of acupuncture can alleviate the symptoms associated with adjuvant hormonal treatments for early breast cancer in a clinically meaningful way. This is, to our knowledge, the first evaluation of a real world long running service and provides an opportunity to assess whether results align with scientific evidence.

We acknowledge many limitations to this evaluation. Despite its longevity, the numbers of women treated are small. While NADA is often delivered in groups of up to 20 or more (Rachel Peckham, 'The role and the impact of the NADA protocol', unpublished MSc thesis, University of Westminster, 2005) the small size of the available treatment rooms limited group size. Additionally, fully supported resources, such as dedicated funding, were not in place in the early years of the service. Full management support was eventually garnered as the service established a reputation and consistently received referrals from oncologists and self-referral.

Incompleteness of the data is another limitation. A service is not a research study and service users' expectations of using a service differ from those of participants in a research study. Although therapists stressed the importance of returning questionnaires for monitoring the service, it was not necessarily a priority for service users to do this, as illustrated by the non-returns at EOT, $4-$ and $18-$ weeks (71\%, $57 \%$ and $49 \%$ ). In the research study, 48/51 (94\%) of women returned both baseline and EOT questionnaires, falling to $90 \%$ and $78 \%$ at 4 - and 18 - week follow up. Longevity of the service is another factor, as some data (mostly documents recording referrals for women who then did not commence treatment) were lost in office refurbishments.

Nevertheless, the data offer many interesting insights. Women adhered to treatment, with $92 \%$ completing a full course of eight treatments. This suggests that the intervention was acceptable and that women experienced sufficient benefit to invest time in travelling to the hospital and having treatment. NADA acupuncture was also safe with only two formally recorded adverse events in over 2285 treatments. 


\section{HFNS frequency}

HFNS frequency analysis shows a significant reduction at EOT and this $44 \%(p<0.0001)$ reduction compares favourably with EOT results of other research studies. Walker et al reported a $50 \%(p<.001)$ reduction after 16 body acupuncture treatments over 12 weeks, a reduction reported as equivalent to venlafaxine [14]. A systematic review of six randomised controlled trials (RCTs) by Frisk et al reported a mean reduction of $43.2 \%$ from baseline to end of acupuncture (range 5-12 weeks of treatment, $n=172$ ) [18]. These comparisons raise the question of dose. Our dosage of eight treatments over eight weeks lies at the lower end of these scales; it would be interesting to compare the results of NADA following an extended treatment regimen.

We note that our inclusion criterion of $\geq 4$ HFNS per 24 -hour period for $\geq 3$ months is higher than that used for most studies of HFNS. (We also note that despite 7\% of women reporting fewer than this, the median number of HFNS at baseline was 9.6 (IQR 7.3) per day). A systematic review of RCTs of active interventions for HFNS reports entry criteria from as few as four HFNS per week for one month, with nine of the 13 studies reported set at $\geq 2$ per day [38]. Our criteria may be classified as "high frequency", defined as $\geq 12$ hot flushes and $\geq 3$ night sweats a week [7].

Our follow up data suggest that improvement was maintained from EOT to 18 weeks. This $46.7 \%(p<0.0001)$ reduction again compares favourably with Frisk's reported $45.6 \%$ at final follow-up (mean 6 months, range 3-9, $n=153$ ) [18]. However, our result must be interpreted with caution due to missing data. It is unclear whether women were not motivated to return hot flush diaries because they did not experience benefit, or whether HFNS were no longer troublesome enough to warrant completing the paperwork.

\section{HFNS as a problem}

There is debate in the literature as to whether frequency counts are the most appropriate measure of HFNS, as frequency alone may not accurately assess the impact of HFNS on a woman's life [6,7]. While frequency is often the main outcome in assessments of treatment, reducing the interference of HFNS and improving quality of life may be more meaningful measures of a successful intervention [7].

The HFRS captures the impact of HFNS on women's lives and on their quality of life [34]. NADA service HFRS data show clinically and statistically significant improvement in HFNS as a problem in both the short- and long-term. We compared service results with HFRS results from an RCT comparing nurse-led cognitive behavioural therapy (CBT) with usual care for breast cancer related HFNS (Table 5) [39]. NADA maintained a clinically meaningful reduction of $\geq 2$ points at all measurement points. While it appears to have performed less well than CBT (-2.4 points compared to -3.2 points at final follow-up), it appears to be superior to usual care (-1 point at final follow-up).

We also compared our HFNS frequency with the CBT study, which showed the NADA service users had a greater decrease in frequency (-23 HFNS/week) than those practising CBT (-16/week) and usual care (-7/week) at the final follow-up points.

\section{Associated menopausal symptoms}

Our data show improvements in a range of symptoms associated with the menopause at EOT, including depressed mood, somatic symptoms, memory/concentration, vasomotor symptoms, anxiety/fears, and sleep problems. Improvements were maintained at the 4-week follow-up for all but depressed mood and memory/concentration. However, benefit at 18 weeks post-treatment was sustained for anxiety/fears and vasomotor symptoms only. The benefit at EOT accords with results of a systematic review of six RCTs (207 participants) that reported on validated menopausal scales [20], but falls short of the 3-months reported in another systematic review of the maintenance effect of acupuncture on menopause symptoms (five studies analysed) [17].

\section{Comparison with our previous NADA research data}

Finally, this service was set up on the model of our previous research. In comparing the outcomes of the service and research we found that overall responses observed in the service users compared favourably with the results collected more rigorously from the research.

\section{Recommendations}

This evaluation comes at a time when the service is planning to update its scope and aims. In shaping a new service, we have discussed whether to dispense with the hot flush diaries and rely on the HFRS, which would be easier for service users to complete. However, clinically we have found that keeping hot flush diaries often helps women to fully realise the extent of their HFNS, as well as helping them to identify patterns, which may provide insight and a measure of control. We recommend completing diaries for a week rather than a fortnight.

We also recommend replacing the WHQ with the Hot Flash Related Daily Interference Scale (HFRDIS). This 10-item questionnaire measures impact of HFNS on daily activities and quality of life in the past week [34]. This much shorter questionnaire may simplify data completion for women, some of whom struggled with the paperwork in the service and would also simplify analysis. 


\section{Conclusion}

This first analysis of a long-term acupuncture service for HFNS and first long-term report of outcomes for NADA compares favourably with outcomes for other studies for improving consequences of adjuvant hormonal treatments for breast cancer, including frequency of HFNS and HFNS as a problem, as well as menopausal health related quality of life. In day-to-day clinical practice, NADA appears to be a safe, effective intervention for women who do not wish to use pharmacological means to control their HFNS.

\section{Declarations}

\section{Funding}

This work has been made possible by charitable funding from the charities Lynda Jackson Macmillan Centre and the East and North Hertfordshire Hospitals' Charity, as well as from donations from numerous private individuals, and from Dr Richard Ashford.

\section{Declarations of interest/Competing interests}

The salaries of Beverley de Valois, Pam Thorpe, Karen Corbishley and Tarsem Degun are funded by the East and North Hertfordshire Hospitals' Charities.

\section{Availability of data and material}

Not applicable.

\section{Code availability}

Not applicable

\section{Authors' contributions}

Conceptualization: Beverley de Valois, Teresa Young

Data Curation: Teresa Young

Formal analysis: Teresa Young

Funding acquisition: Teresa Young, Pam Thorpe, Karen Corbishley

Investigation: Pam Thorpe, Tarsem Degun

Methodology: Teresa Young, Beverley de Valois

Project administration: Pam Thorpe, Karen Corbishley

Resources: Teresa Young, Pam Thorpe, Karen Corbishley

Supervision: Teresa Young, Beverley de Valois

Validation: Teresa Young, Beverley de Valois

Visualisation: Teresa Young, Beverley de Valois.

Writing - original draft preparation: Beverley de Valois, Teresa Young

Writing - review and editing: Beverley de Valois, Teresa Young, Pam Thorpe, Tarsem Degun, Karen Corbishley

\section{Ethics approvals}


This is a service evaluation and in line with guidance from the United Kingdom's Health Research Authority (HRA), service evaluations do not require ethical review http://www.hradecisiontools.org.uk/research/docs/DefiningResearchTable_Oct2017-1.pdf

Professor Jane Maher, Medical Director of the Lynda Jackson Macmillan Centre, approved data collection in 2005. Data collection for this service accorded with ethical standards laid down by the 1964 Declaration of Helsinki and its later amendments. Individuals gave written consented to have this treatment after receiving information about the intervention and the opportunity to ask questions. In giving informed consent, individuals consented to be involved in this evaluation. This dataset stretches back to 2005 and at the time this service started, ethical approval was not required for publication of clinical outcome measures.

\section{Consent to participate}

The authors affirm that service users provided informed consent to participate in this service.

\section{Consent for publication}

The authors affirm that service users provided informed consent for their data to be used in this evaluation.

\section{Acknowledgments}

The authors acknowledge the contributions of the following people, from whom we have obtained permission to be acknowledged: Professor Jane Maher, former Medical Director of the Lynda Jackson Macmillan Centre, for leadership and emphasis on the importance of monitoring and data collection; Rosemary Lucey, former manager of the LJMC, for involvement in the initial research and for continued management support for establishing and maintaining the NADA service; Dr Richard Ashford, Consultant Clinical Oncologist (retired) for funding and support, Rachel Peckham, NADA GB trainer, for training and technical advice; Diane Back, LJMC volunteer, for many years of data input; Cherry Mackie, former Complementary Therapy Co-ordinator, for initial set up and running of the service: Jill Preston, former Complementary Therapy Coordinator, for continuation of running of the service; Raten Davies, NADA therapist; Gay Walker, researcher; Dr Michael Smith (deceased), Founding Chairperson of NADA for inspiration, support and the "spirit of NADA".

\section{References}

1. Marsden J (2019) British Menopause Society Consensus Statement: the risks and benefits of HRT before and after a breast cancer diagnosis. Post Reprod Health 25:33-37

2. Cancer Research UK (no date) Breast cancer statistics. Cancer Research UK, https://www.cancerresearchuk.org/health-professional/cancerstatistics/statistics-by-cancer-type/breast-cancer\#heading-Six. Accessed 29 July 2021

3. Moon Z, Hunter MS, Moss-Morris R, Hughes LD (2017) Factors related to the experience of menopausal symptoms in women prescribed tamoxifen. J Psychosom Obstet Gynaecol 38:226-235

4. Love RR, Feyzi JM (1993) Reductions in vasomotor symptoms from tamoxifen over time. J Natl Cancer Inst 85:673-674

5. Fenlon D, Morgan A, Khambaita P, Mistry P, Dunn J, Ah-See ML, Pennery E, Hunter MS (2017) Management of hot flushes in UK breast cancer patients: clinician and patient perspectives. J Psychosom Obstet Gynaecol 38:276-283

6. Sturdee DW, Hunter MS, Maki PM, Gupta P, Sassarini J, Stevenson JC, Lumsden MA (2017) The menopausal hot flush: a review. Climacteric 20:296-305

7. Thurston RC, Bromberger JT, Joffe H, Avis NE, Hess R, Crandall CJ, Chang Y, Green R, Matthews KA (2008) Beyond frequency: who is most bothered by vasomotor symptoms? Menopause 15:841-847

8. Santen RJ, Stuenkel CA, Davis SR, Pinkerton JV, Gompel A, Lumsden MA (2017) Managing menopausal symptoms and associated clinical issues in breast cancer survivors. J Clin Endocrinol Metab 102:3647-3661

9. Tran S, Hickey M, Saunders C, Ramage L, Cohen PA (2021) Nonpharmacological therapies for the management of menopausal vasomotor symptoms in breast cancer survivors. Support Care Cancer 29:1183-1193

10. McCowan C, Thompson AM (2012) The importance of nonpharmacogenetic factors in endocrine therapy. Pharmacogenomics 13:721-728

11. Mao JJ, Leed R, Bowman MA, Desai K, Bramble M, Armstrong K, Barg F (2012) Acupuncture for hot flashes: decision making by breast cancer survivors. J Am Board Fam Med 25:323-332

12. Wang XP, Zhang DJ, Wei XD, Wang JP, Zhang DZ (2018) Acupuncture for the relief of hot flashes in breast cancer patients: a systematic review and meta-analysis of randomized controlled trials and observational studies. J Cancer Res Ther 14:S600-S608

Page $8 / 18$ 
13. Mao JJ, Bowman MA, Xie SX, Bruner D, DeMichele A, Farrar JT (2015) Electroacupuncture versus gabapentin for hot flashes among breast cancer survivors: a randomized placebo-controlled trial. J Clin Oncol 33:3615-3620

14. Walker EM, Rodriguez Al, Kohn B, Ball RM, Pegg J, Pocock JR, Nunez R, Peterson E, Jakary S, Levine RA (2010) Acupuncture versus venlafaxine for the management of vasomotor symptoms in patients with hormone receptor-positive breast cancer: a randomized controlled trial. J. Clin. Oncol. 28: 634-640. https://doi.org10.1200/JC0.2009.23.5150

15. Johnson A, Roberts L, Elkins G (2019) Complementary and alternative medicine for menopause. J Evid Based Integr Med $24: 2515690 \times 19829380$

16. Hunter M (1992) The Women's Health Questionnaire: a measure of mid-aged women's perceptions of their emotional and physical health. Psychol Health 7:45-54

17. Chien TJ, Liu CY, Fang CJ, Kuo CY (2020) The maintenance effect of acupuncture on breast cancer-related menopause symptoms: a systematic review. Climacteric 23:130-139

18. Frisk JW, Hammar ML, Ingvar M, Spetz Holm A-CE (2014) How long do the effects of acupuncture on hot flashes persist in cancer patients? Support. Care Cancer 22:1409-1415

19. Bokmand S, Flyger H (2013) Acupuncture relieves menopausal discomfort in breast cancer patients: a prospective, double blinded, randomized study. Breast 22:320-323

20. Chien TJ, Hsu CH, Liu CY, Fang CJ (2017) Effect of acupuncture on hot flush and menopause symptoms in breast cancer- a systematic review and meta-analysis. PLoS ONE 12:e0180918

21. de Valois B, Young T, Robinson N, McCourt C, Maher EJ (2010) Using traditional acupuncture for breast cancer-related hot flashes and night sweats. J Altern Complement Med 16:1047-1057

22. de Valois B, Young T, Robinson N, McCourt C, Maher EJ (2012) NADA ear acupuncture for breast cancer treatment-related hot flashes and night sweats: an observational study. Med Acupunct 24:256-268

23. Frisk J, Kallstrom AC, Wall N, Fredrikson M, Hammar M (2012) Acupuncture improves heath-related quality of life (HRQoL) and sleep in women with breast cancer and hot flushes. Support Care Cancer 20:715-724

24. Lesi G, Razzini G, Musti MA, Stivanello E, Petrucci C, Benedetti B, Rondini E, Ligabue MB, Scaltriti L, Botti A, Artioli F, Mancuso P, Cardini F, Pandolfi P (2016) Acupuncture as an integrative approach for the treatment of hot flashes in women with breast cancer: a prospective multicenter randomized controlled trial (AcCliMaT). J Clin Oncol 34:1795-1802

25. Frieden TR (2017) Evidence for health decision making - beyond randomized, controlled trials. N. Engl. J. Med. 377: 465-475. https://doi.org10.1056/NEJMra1614394

26. National Acupuncture Detoxification Association (2021) What is the NADA protocol? https://acudetox.com/nada-protocol/. Accessed November 102021

27. NADA GB (2021) NADA Protocol http://www.nadagbacupuncture.co.uk/about-nada-gb/nada-protocol. Accessed November 102021

28. Zayas J, Ruddy KJ, Olson JE, Couch FJ, Bauer BA, Mallory MJ, Yang P, Zahrieh D, Athreya AP, Loprinzi CL, Cathcart-Rake EJ (2020) Realworld experiences with acupuncture among breast cancer survivors: a cross-sectional survey study. Support Care Cancer 28:5833-5838

29. Cramer H (2021) Learning to fly: conceptions and misconceptions, uses and misuses of pilot studies in clinical research. $J$ Altern Complement Med 27:531-534

30. Hoffmann TC, Glasziou PP, Boutron I, Milne R, Perera R, Moher D, Altman DG, Barbour V, Macdonald H, Johnston M, Lamb SE, Dixon-Woods M, McCulloch P, Wyatt JC, Chan A-W, Michie S (2014) Better reporting of interventions: template for intervention description and replication (TIDieR) checklist and guide. BMJ 348:g1687

31. World Medical Association (2018) WMA Declaration of Helsinki - ethical principles for medical research involving human subjects. World Medical Association https://www.wma.net/policies-post/wma-declaration-of-helsinki-ethical-principles-for-medical-research-involvinghuman-subjects/. Accessed 13 July 2021

32. Walker G, de Valois B, Davies R, Young T, Maher EJ (2007) Ear acupuncture for hot flushes - the perceptions of women with breast cancer. Complement Ther Clin Pract 13:250-257

33. Hunter M, Liao KL (1995) A psychological analysis of menopausal hot flushes. Br J Clin Psychol 34:589-599

34. Hunter MS, Nuttall J, Fenlon D (2019) A comparison of three outcome measures of the impact of vasomotor symptoms on women's lives. Climacteric 22:419-423

35. Fenlon D, Nuttall J, May C, Raftery J, Fields J, Kirkpatrick E, Abab J, Ellis M, Rose T, Khambhaita P, Galanopoulou A, Maishman T, Haviland J, Griffiths G, Turner L, Hunter M (2018) MENOS4 trial: a multicentre randomised controlled trial (RCT) of a breast care nurse delivered cognitive behavioural therapy (CBT) intervention to reduce the impact of hot flushes in women with breast cancer: study protocol. BMC Womens Health 18:63 
36. Girod I, Abetz L, de la Loge C, Fayol-Paget C, Hunter M (2004) WHQ Women's Health Questionnaire User Manual. MAPI Research Institute, Lyon

37. Witt CM, Pach D, Brinkhaus B, Wruck K, Tag B, Mank S, Willich SN (2009) Safety of acupuncture: results of a prospective observational study with 229,230 patients and introduction of a medical information and consent form. Forsch Komplementmed 16:91-97

38. Johns C, Seav SM, Dominick SA, Gorman JR, Li H, Natarajan L, Mao JJ, Irene Su H (2016) Informing hot flash treatment decisions for breast cancer survivors: a systematic review of randomized trials comparing active interventions. Breast Cancer Res Treat 156:415-426

39. Fenlon D, Maishman T, Day L, Nuttall J, May C, Ellis M, Raftery J, Turner L, Fields J, Griffiths G, Hunter MS (2020) Effectiveness of nurse-led group CBT for hot flushes and night sweats in women with breast cancer: results of the MENOS4 randomised controlled trial. Psychooncology 29:1514-1523

\section{Tables}

Table 1 Demographic and clinical details at baseline $(n=300)$ 


\begin{tabular}{|c|c|}
\hline \multicolumn{2}{|l|}{ AGE } \\
\hline Mean (Median) & $53(52)$ \\
\hline Range & $33-78$ \\
\hline Missing & 6 \\
\hline DEMOGRAPHIC CHARACTERISTICS & n (\%) \\
\hline \multicolumn{2}{|l|}{ Marital status } \\
\hline Single & $25(8.3)$ \\
\hline Married & $165(55)$ \\
\hline Re-married & $34(11.3)$ \\
\hline Living with partner & $24(8)$ \\
\hline Separated & $9(3)$ \\
\hline Divorced & $21(7)$ \\
\hline Widowed & $15(5)$ \\
\hline Missing & $7(2.3)$ \\
\hline \multicolumn{2}{|l|}{ Ethnic background } \\
\hline Asian - other & $5(1.6)$ \\
\hline Black (African, British, Caribbean) & $10(3.3)$ \\
\hline Indian & $17(5.7)$ \\
\hline Pakistani & $3(1)$ \\
\hline White British & $222(74)$ \\
\hline White other & $20(6.7)$ \\
\hline Other & $6(2)$ \\
\hline Missing & $17(5.7)$ \\
\hline \multicolumn{2}{|l|}{ Education } \\
\hline Less than compulsory & $22(7.3)$ \\
\hline Compulsory & $113(37.7)$ \\
\hline Post compulsory & $68(22.7)$ \\
\hline University & $53(17.7)$ \\
\hline Post-graduate & $28(9.3)$ \\
\hline Missing & $16(5.3)$ \\
\hline \multicolumn{2}{|l|}{ Current employment status } \\
\hline Retired & $64(21)$. \\
\hline Not working & $51(17)$ \\
\hline Working part-time & $100(33.3)$ \\
\hline Working full-time & $76(25.3)$ \\
\hline Missing & $9(3)$ \\
\hline \multicolumn{2}{|l|}{ CLINICAL CHARACTERISTICS } \\
\hline \multicolumn{2}{|l|}{ Current adjuvant hormonal therapy (AHT) } \\
\hline Anastrozole & $47(15.7)$ \\
\hline Exemestane & $13(4.3)$ \\
\hline Letrozole & $25(8.3)$ \\
\hline
\end{tabular}

Page $11 / 18$ 


\begin{tabular}{|c|c|}
\hline Tamoxifen & $191(63.7)$ \\
\hline AHT plus Zoladex & $5(1.7)$ \\
\hline Other & $1(0.3)$ \\
\hline Missing & $18(6)$ \\
\hline \multicolumn{2}{|l|}{ Time receiving adjuvant hormonal therapy (AHT) } \\
\hline$<6$ months & $30(10)$ \\
\hline 6-12 months & $130(43.3)$ \\
\hline $1-2$ years & $78(26)$ \\
\hline $2-3$ years & $19(6.3)$ \\
\hline$\geq 3$ years & $9(3)$ \\
\hline Missing & $34(11.3)$ \\
\hline \multicolumn{2}{|l|}{ Cancer treatment history } \\
\hline \multicolumn{2}{|l|}{ Surgery } \\
\hline Mastectomy & $106(35.5)$ \\
\hline Wide Local Excision & $171(57)$ \\
\hline Other & $2(0.6)$ \\
\hline No surgery & $2(0.6)$ \\
\hline Missing & $19(6.3)$ \\
\hline \multicolumn{2}{|l|}{ Radiotherapy } \\
\hline Radiotherapy - yes & $164(54.7)$ \\
\hline Radiotherapy - no & $36(12)$ \\
\hline Missing & $100(33.3)$ \\
\hline \multicolumn{2}{|l|}{ Chemotherapy } \\
\hline Neo-adjuvant - yes & $34(11.3)$ \\
\hline Neo-adjuvant - no & $238(79.3)$ \\
\hline Neo-adjuvant - missing & $28(9.3)$ \\
\hline Chemotherapy adjuvant - yes & $122(40.7)$ \\
\hline Chemotherapy adjuvant - no & $142(47.3)$ \\
\hline Chemotherapy adjuvant - missing & $36(12)$ \\
\hline \multicolumn{2}{|l|}{ Menopausal status } \\
\hline Perimenopause (last period within previous year) & $36(12)$ \\
\hline Menopause (no period within previous $1-5$ years) & $86(28.7)$ \\
\hline Postmenopausal (no period in $>5$ years) & $48(16)$ \\
\hline Missing & $130(43.3)$ \\
\hline \multicolumn{2}{|l|}{ History of HRT } \\
\hline Have taken HRT & $91(30.3)$ \\
\hline Have not taken HRT & $187(62.3)$ \\
\hline Missing & $22(7.3)$ \\
\hline \multicolumn{2}{|l|}{ Co-morbidities self-reported by patients } \\
\hline \multicolumn{2}{|l|}{ Number of co-morbidities } \\
\hline 0 & $78(26)$ \\
\hline
\end{tabular}

Page 12/18 


\begin{tabular}{|ll|}
1 & $81(27)$ \\
3 & $68(22.7)$ \\
4 & $31(10.3)$ \\
5 & $20(6.7)$ \\
$6-11$ & $11(3.7)$ \\
\hline Co-morbidities* & $11(3.7)$ \\
Allergy & \\
Anaemia & $42(14)$ \\
Asthma & $8(2.7)$ \\
Cardiovascular other than hypertension & $32(10.7)$ \\
Depression & $7(2.3)$ \\
Diabetes & $54(18)$ \\
Digestive diseases & $16(5.3)$ \\
Genitourinary disorders & $25(8.3)$ \\
Musculo-skeletal & $11(3.7)$ \\
Respiratory & $80(26.7)$ \\
\hline * Other co-morbidities reported include fatigue, anxiety, Crohn's disease, hypothyroidism \\
\hline
\end{tabular}

Table 2 NADA HFNS frequency (per day)

\begin{tabular}{|lllll|}
\hline & Baseline & EOT & Post-tx 4 & Post-tx 18 \\
& $\mathrm{n}=\mathbf{2 0 5 / 3 0 0}$ & $\mathrm{n=205/300}$ & $\mathrm{n=166/300}$ & $\mathrm{n=140/300}$ \\
\hline Mean (Standard Deviation) & $10.9(8.1)$ & $6.9(5.0)$ & $6.8(4.9)$ & $7.2(5.0)$ \\
\hline 95\% Confidence Interval & $9.8-12.0$ & $6.2-7.6$ & $6.0-7.5$ & $6.4-8.1$ \\
\hline Median (Inter Quartile Range) & $9.6(7.3)$ & $5.7(5.8)$ & $5.6(6.1)$ & $6.3(6.5)$ \\
\hline Minimum mean score & 1.57 & 0 & 0 & 0 \\
\hline Maximum mean score & 94.3 & 29 & 24.4 & 22.7 \\
\hline Range & 92.73 & 29 & 24.4 & 22.7 \\
\hline
\end{tabular}

Table 3 - Changes in HFRS and WHQ at four time points 


\begin{tabular}{|c|c|c|c|c|c|c|c|c|c|}
\hline & $\begin{array}{l}\text { Baseline } \\
(n=202)\end{array}$ & $\begin{array}{l}\text { EOT } \\
(n=202)\end{array}$ & & $\begin{array}{l}\text { Baseline } \\
(n=162)\end{array}$ & $\begin{array}{l}\text { Post-tx } \\
4 \\
(n=162)\end{array}$ & & $\begin{array}{l}\text { Baseline } \\
(n=133)\end{array}$ & $\begin{array}{l}\text { Post-tx } \\
18 \\
(n=133)\end{array}$ & \\
\hline & $\begin{array}{l}\text { Mean } \\
\text { (SD) }\end{array}$ & $\begin{array}{l}\text { Mean } \\
\text { (SD) }\end{array}$ & $\begin{array}{l}\Delta \\
\text { BASELINE } \\
\text {-EOT }\end{array}$ & $\begin{array}{l}\text { Mean } \\
\text { (SD) }\end{array}$ & $\begin{array}{l}\text { Mean } \\
(\mathrm{SD})\end{array}$ & $\begin{array}{l}\Delta \\
\text { BASELINE } \\
-\frac{4}{4} \text { Post-Tx }\end{array}$ & $\begin{array}{l}\text { Mean } \\
\text { (SD) }\end{array}$ & $\begin{array}{l}\text { Mean } \\
(\mathrm{SD})\end{array}$ & $\begin{array}{l}\Delta \\
\text { BASELINE } \\
- \text { Post-Tx } \\
18\end{array}$ \\
\hline HFRS & $\begin{array}{l}7.56 \\
(1.70)\end{array}$ & $\begin{array}{l}5.42 \\
(2.55)\end{array}$ & 2.14 & $\begin{array}{l}7.37 \\
(1.72)\end{array}$ & $\begin{array}{l}4.90 \\
(2.53)\end{array}$ & 2.47 & $\begin{array}{l}7.37 \\
(1.71)\end{array}$ & $\begin{array}{l}5.18 \\
(2.56)\end{array}$ & 2.19 \\
\hline \multicolumn{10}{|l|}{ WHQ domain } \\
\hline Anxiety/fears (ANX) & $\begin{array}{l}0.39 \\
(0.33)\end{array}$ & $\begin{array}{l}0.27 \\
(0.27)\end{array}$ & 0.12 & $\begin{array}{l}0.38 \\
(0.32)\end{array}$ & $\begin{array}{l}0.23 \\
(0.28)\end{array}$ & 0.15 & $\begin{array}{l}0.38 \\
(0.33)\end{array}$ & $\begin{array}{l}0.28 \\
(0.30)\end{array}$ & 0.10 \\
\hline Attractiveness (ATT) & $\begin{array}{l}0.61 \\
(0.29)\end{array}$ & $\begin{array}{l}0.65 \\
(0.31)\end{array}$ & -0.04 & $\begin{array}{l}0.63 \\
(0.29)\end{array}$ & $\begin{array}{l}0.66 \\
(0.31)\end{array}$ & -0.03 & $\begin{array}{l}0.63 \\
(0.29)\end{array}$ & $\begin{array}{l}0.66 \\
(0.32)\end{array}$ & -0.03 \\
\hline $\begin{array}{l}\text { Depressed mood } \\
\text { (DEP) }\end{array}$ & $0.31(0.17)$ & $\begin{array}{l}0.25 \\
(0.14)\end{array}$ & 0.06 & $\begin{array}{l}0.30 \\
(0.18)\end{array}$ & $\begin{array}{l}0.27 \\
(0.16)\end{array}$ & 0.03 & $\begin{array}{l}0.29 \\
(0.17)\end{array}$ & $\begin{array}{l}0.27 \\
(0.16)\end{array}$ & 0.02 \\
\hline $\begin{array}{l}\text { Memory/concentration } \\
\text { (MEM) }\end{array}$ & $0.64(0.36)$ & $\begin{array}{l}0.57 \\
(0.36)\end{array}$ & 0.07 & $\begin{array}{l}0.63 \\
(0.36)\end{array}$ & $\begin{array}{l}0.60 \\
(0.38)\end{array}$ & 0.03 & $\begin{array}{l}0.65 \\
(0.36)\end{array}$ & $\begin{array}{l}0.61 \\
(0.36)\end{array}$ & 0.04 \\
\hline $\begin{array}{l}\text { Menstrual symptoms } \\
\text { (MEN) }\end{array}$ & $\begin{array}{l}0.34 \\
(0.24)\end{array}$ & $0.30(0.24)$ & 0.04 & $\begin{array}{l}0.34 \\
(0.24)\end{array}$ & $\begin{array}{l}0.29 \\
(0.24)\end{array}$ & 0.05 & $\begin{array}{l}0.33 \\
(0.25)\end{array}$ & $\begin{array}{l}0.31 \\
(0.25)\end{array}$ & 0.02 \\
\hline $\begin{array}{l}\text { Sexual behaviour(SEX) } \\
(\mathrm{n}=123 \text { baseline } \\
\text { pairs })^{\star}\end{array}$ & $\begin{array}{l}0.49 \\
(0.32)\end{array}$ & $\begin{array}{l}0.44 \\
(0.37)\end{array}$ & 0.05 & $\begin{array}{l}0.48 \\
(0.32)\end{array}$ & $\begin{array}{l}0.43 \\
(0.33)\end{array}$ & 0.05 & $\begin{array}{l}0.48 \\
(0.31)\end{array}$ & $\begin{array}{l}0.44 \\
(0.32)\end{array}$ & 0.04 \\
\hline Sleep problems (SLE) & $\begin{array}{l}0.64 \\
(0.29)\end{array}$ & $\begin{array}{l}0.48 \\
(0.33)\end{array}$ & 0.16 & $\begin{array}{l}0.62 \\
(0.29)\end{array}$ & $\begin{array}{l}0.51 \\
(0.32)\end{array}$ & 0.11 & $\begin{array}{l}0.64 \\
(0.30)\end{array}$ & $\begin{array}{l}0.58 \\
(0.34)\end{array}$ & 0.06 \\
\hline $\begin{array}{l}\text { Somatic } \\
\text { symptoms(SOM) }\end{array}$ & $\begin{array}{l}0.52 \\
(0.23)\end{array}$ & $\begin{array}{l}0.43 \\
(0.23)\end{array}$ & 0.09 & $\begin{array}{l}0.51 \\
(0.23)\end{array}$ & $\begin{array}{l}0.47 \\
(0.25)\end{array}$ & 0.04 & $\begin{array}{l}0.50 \\
(0.23)\end{array}$ & $\begin{array}{l}0.47 \\
(0.25)\end{array}$ & 0.03 \\
\hline $\begin{array}{l}\text { Vasomotor symptoms } \\
\text { (VAS) }\end{array}$ & $\begin{array}{l}0.97 \\
(0.14)\end{array}$ & $\begin{array}{l}0.79 \\
(0.33)\end{array}$ & 0.18 & $\begin{array}{l}0.97 \\
(0.14)\end{array}$ & $\begin{array}{l}0.79 \\
(0.33)\end{array}$ & 0.18 & $0.96(0.15)$ & $\begin{array}{l}0.86 \\
(0.30)\end{array}$ & 0.10 \\
\hline \multicolumn{10}{|l|}{ Notes: } \\
\hline \multicolumn{10}{|c|}{ Higher scores are associated with worse symptomology and quality of life. } \\
\hline \multicolumn{10}{|c|}{ Clinically significant changes are highlighted in bold. } \\
\hline \multicolumn{10}{|c|}{ HFRS: A change of 2 points is considered clinically meaningful. } \\
\hline \multicolumn{10}{|c|}{ WHQ: A change of $0.10-0.20$ is clinically meaningful. } \\
\hline \multicolumn{10}{|c|}{$\begin{array}{l}\text { Sexual behaviour (SEX): only } 123 \text { patients completed baseline and EOT (not } 202 \text { as for other scales), falling to } 100 \text { and } 82 \text { at } 4 \text { and } 18 \\
\text { weeks respectively. }\end{array}$} \\
\hline
\end{tabular}

TABLE 4 Comparison of NADA research participants (RP) with NADA service users (SU): mean changes in outcome measures 


\begin{tabular}{|c|c|c|c|c|c|c|c|c|c|c|}
\hline & $\begin{array}{l}\text { Time Period } \\
\text { Baseline to: }\end{array}$ & Group & $\mathrm{n}=$ & Change & $\begin{array}{l}\text { Lower } \\
(5 \%)\end{array}$ & $\begin{array}{l}\text { Upper } \\
(95 \%)\end{array}$ & $\begin{array}{l}\mathrm{t}^{\prime} \\
\text { (paired) }\end{array}$ & $\mathrm{p}<$ & $\begin{array}{l}\text { 't' } \\
\text { (unpaired) }\end{array}$ & p \\
\hline \multicolumn{11}{|l|}{ HFNS Frequency } \\
\hline \multirow[t]{6}{*}{ Mean \% reduction } & \multirow[t]{2}{*}{ EOT } & $\mathrm{RP}$ & 47 & $35.9 \%$ & $25.4 \%$ & $45.4 \%$ & 5.8 & 0.0001 & 1.5 & NS \\
\hline & & SU & 205 & $44.4 \%$ & $38.7 \%$ & $49.5 \%$ & 12.0 & 0.0001 & & \\
\hline & \multirow[t]{2}{*}{ Post-tx 4} & $\mathrm{RP}$ & 45 & $37.5 \%$ & $25.4 \%$ & $47.6 \%$ & 5.3 & 0.0001 & 1.8 & NS \\
\hline & & su & 166 & $48.2 \%$ & $41.7 \%$ & $54.0 \%$ & 11.1 & 0.0001 & & \\
\hline & \multirow[t]{2}{*}{ Post-tx 18} & $\mathrm{RP}$ & 38 & $37.1 \%$ & $24.8 \%$ & $47.4 \%$ & 5.3 & 0.0001 & 1.4 & NS \\
\hline & & SU & 141 & $46.7 \%$ & $37.4 \%$ & $54.6 \%$ & 7.8 & 0.0001 & & \\
\hline \multicolumn{11}{|c|}{ Hot Flush Rating Scale (HFRS) } \\
\hline & \multirow[t]{2}{*}{ EOT } & $\mathrm{RP}$ & 48 & 2.15 & 1.55 & 2.74 & 7.2 & 0.0001 & 0.9 & NS \\
\hline & & su & 197 & 2.14 & 1.80 & 2.48 & 12.3 & 0.0001 & & \\
\hline & \multirow[t]{2}{*}{ Post-tx 4} & $\mathrm{RP}$ & 46 & 2.17 & 1.59 & 2.75 & 7.5 & 0.0001 & 2.1 & 0.04 \\
\hline & & SU & 155 & 2.47 & 2.07 & 2.87 & 12.26 & 0.0001 & & \\
\hline & \multirow[t]{2}{*}{ Post-tx 18} & $\mathrm{RP}$ & 31 & 1.81 & 1.17 & 2.44 & 5.8 & 0.0001 & 2.2 & 0.03 \\
\hline & & SU & 138 & 2.19 & 1.76 & 2.63 & 11.4 & 0.0001 & & \\
\hline \multicolumn{11}{|c|}{ Women's Health Questionnaire (WHQ) } \\
\hline \multirow[t]{6}{*}{ ANX } & \multirow[t]{2}{*}{ EOT } & $\mathrm{RP}$ & 47 & .10 & .03 & .17 & 2.9 & 0.006 & 0.4 & NS \\
\hline & & SU & 202 & .12 & .07 & .16 & 5.4 & 0.0001 & & \\
\hline & \multirow[t]{2}{*}{ Post-tx 4} & $\mathrm{RP}$ & 45 & .09 & .01 & .17 & 2.3 & 0.03 & 1.4 & NS \\
\hline & & SU & 162 & .15 & .11 & .19 & 7.0 & 0.0001 & & \\
\hline & \multirow[t]{2}{*}{ Post-tx 18} & $\mathrm{RP}$ & 39 & .06 & -.02 & .15 & 1.5 & 0.2 & 0.8 & NS \\
\hline & & SU & 133 & .10 & .05 & .14 & 4.1 & 0.0001 & & \\
\hline \multirow[t]{6}{*}{ ATT } & \multirow[t]{2}{*}{ EOT } & $\mathrm{RP}$ & 44 & .06 & -.04 & .15 & 1.2 & 0.3 & -1.9 & NS \\
\hline & & SU & 193 & -.04 & -.08 & .01 & -1.6 & 0.2 & & \\
\hline & \multirow[t]{2}{*}{ Post-tx 4} & $\mathrm{RP}$ & 44 & .07 & -.04 & .18 & 1.2 & 0.3 & -1.7 & NS \\
\hline & & SU & 154 & -.03 & -.09 & .02 & -1.2 & 0.3 & & \\
\hline & \multirow[t]{2}{*}{ Post-tx 18} & $\mathrm{RP}$ & 37 & .01 & -.09 & .12 & .3 & 0.8 & -0.7 & NS \\
\hline & & SU & 124 & -.03 & .09 & .03 & -.9 & 0.4 & & \\
\hline \multirow[t]{6}{*}{ DEP } & \multirow[t]{2}{*}{ EOT } & $\mathrm{RP}$ & 47 & .15 & .08 & .22 & 4.1 & 0.0001 & -2.5 & 0.03 \\
\hline & & SU & 202 & .06 & .03 & .08 & 4.3 & 0.0001 & & \\
\hline & \multirow[t]{2}{*}{ Post-tx 4} & $\mathrm{RP}$ & 44 & .09 & .03 & .15 & 2.9 & 0.006 & -1.7 & NS \\
\hline & & SU & 162 & .03 & .00 & .06 & 2.0 & 0.05 & & \\
\hline & \multirow[t]{2}{*}{ Post-tx 18} & $\mathrm{RP}$ & 39 & .02 & -.06 & .09 & .4 & 0.7 & 0.06 & NS \\
\hline & & SU & 133 & .02 & -.01 & .05 & 1.4 & 0.2 & & \\
\hline \multirow[t]{5}{*}{ MEM } & \multirow[t]{2}{*}{ EOT } & $\mathrm{RP}$ & 47 & .12 & .02 & .22 & 2.4 & 0.03 & -0.8 & NS \\
\hline & & SU & 202 & .07 & .03 & .12 & 3.2 & 0.001 & & \\
\hline & Post-tx 4 & $\mathrm{RP}$ & 46 & .08 & -.02 & .18 & 1.7 & 0.1 & -0.8 & NS \\
\hline & & SU & 162 & .03 & -.02 & .09 & 1.3 & 0.2 & & \\
\hline & Post-tx 18 & $\mathrm{RP}$ & 39 & .13 & .01 & .24 & 2.2 & 0.04 & -1.4 & NS \\
\hline
\end{tabular}

Page 15/18 


\begin{tabular}{|c|c|c|c|c|c|c|c|c|c|c|}
\hline & & SU & 131 & .04 & -.01 & .10 & 1.6 & 0.2 & & \\
\hline \multirow[t]{6}{*}{ MEN } & EOT & $\mathrm{RP}$ & 48 & .06 & .00 & .12 & 2.0 & 0.06 & -0.6 & NS \\
\hline & & SU & 198 & .04 & .01 & .07 & 2.3 & 0.02 & & \\
\hline & Post-tx 4 & $\mathrm{RP}$ & 46 & .05 & -.01 & .11 & 1.9 & 0.07 & -0.03 & NS \\
\hline & & SU & 158 & .05 & .01 & .09 & 2.6 & 0.01 & & \\
\hline & Post-tx 18 & $\mathrm{RP}$ & 40 & .04 & -.03 & .12 & 1.2 & 0.30 & -0.06 & NS \\
\hline & & SU & 133 & .02 & -.02 & .06 & .8 & 0.5 & & \\
\hline \multirow[t]{6}{*}{ SEX } & EOT & $\mathrm{RP}$ & 34 & .08 & -.01 & .17 & 1.8 & 0.09 & -0.06 & NS \\
\hline & & SU & 123 & .05 & -.01 & .10 & 1.8 & 0.08 & & \\
\hline & Post-tx 4 & $\mathrm{RP}$ & 32 & .03 & -.05 & .11 & 0.8 & 0.5 & -0.4 & NS \\
\hline & & SU & 100 & .05 & .00 & .09 & 1.9 & 0.06 & & \\
\hline & Post-tx 18 & $\mathrm{RP}$ & 26 & .06 & -.01 & .14 & 1.7 & 0.1 & -0.4 & NS \\
\hline & & SU & 82 & .04 & -.02 & .10 & 1.3 & 0.3 & & \\
\hline \multirow[t]{6}{*}{ SLE } & EOT & $\mathrm{RP}$ & 48 & .22 & .10 & .31 & 4.9 & 0.0001 & -1.1 & NS \\
\hline & & SU & 202 & .16 & .11 & .21 & 6.5 & .0001 & & \\
\hline & Post-tx 4 & $\mathrm{RP}$ & 46 & .13 & .05 & .21 & 3.2 & 0.003 & -0.4 & NS \\
\hline & & SU & 162 & .11 & .06 & .17 & 4.0 & 0.0001 & & \\
\hline & Post-tx 18 & $\mathrm{RP}$ & 40 & .11 & .01 & .21 & 2.1 & 0.05 & -0.9 & NS \\
\hline & & SU & 133 & .06 & -.01 & .12 & 1.8 & 0.08 & & \\
\hline \multirow[t]{6}{*}{ SOM } & EOT & $\mathrm{RP}$ & 47 & .12 & .06 & .19 & 3.7 & 0.001 & -0.7 & NS \\
\hline & & SU & 200 & .09 & .06 & .12 & 5.8 & 0.0001 & & \\
\hline & Post-tx 4 & $\mathrm{RP}$ & 45 & .07 & .00 & .13 & 2.1 & 0.04 & -0.8 & NS \\
\hline & & SU & 161 & .04 & .01 & .08 & 2.3 & 0.02 & & \\
\hline & Post-tx 18 & $\mathrm{RP}$ & 39 & .04 & -.04 & .12 & 1.1 & 0.3 & -0.3 & NS \\
\hline & & SU & 136 & .03 & -.01 & .06 & 1.6 & 0.2 & & \\
\hline \multirow[t]{6}{*}{ VAS } & EOT & $\mathrm{RP}$ & 46 & .23 & .12 & .34 & 4.3 & 0.0001 & -0.9 & NS \\
\hline & & SU & 199 & .18 & .13 & .11 & 7.5 & 0.0001 & & \\
\hline & Post-tx 4 & $\mathrm{RP}$ & 44 & .14 & .05 & .23 & 3.0 & 0.003 & 0.7 & NS \\
\hline & & SU & 160 & .18 & .12 & .23 & 6.7 & 0.0001 & & \\
\hline & Post-tx 18 & $\mathrm{RP}$ & 39 & .14 & .04 & .24 & 2.9 & 0.006 & -0.7 & NS \\
\hline & & SU & 136 & .10 & .04 & .15 & 3.6 & 0.0001 & & \\
\hline \multicolumn{11}{|c|}{ Notes: For the WHQ and HFRS, negative changes denote deterioration in symptomology and quality of life } \\
\hline \multicolumn{11}{|c|}{$\begin{array}{l}\text { Abbreviations: RP Research Participants; SU Service Users; EOT End of treatment; Post-tx } 4 \text { Four week after EOT; Post-tx } 1818 \text { weeks afte } \\
\text { EOT; NS Not Significant; ANX Anxiety/fears; ATT Attractiveness; DEP Depressed mood; MEM Memory/concentration; MEN Menstrual } \\
\text { symptoms; SEX Sexual behaviour; SLE Sleep problems; SOM Somatic symptoms; VAS Vasomotor symptoms }\end{array}$} \\
\hline
\end{tabular}

Table 5 Comparison of NADA service HFNS frequency and HFRS problem rating scores with Fenlon et al CBT study[1] 


\begin{tabular}{|c|c|c|c|}
\hline \multicolumn{4}{|l|}{ HFNS Frequency (per week) } \\
\hline & \multirow[t]{2}{*}{ NADA (median IQR, n) } & CBT (median IQR) & Usual Care (median IQR) \\
\hline & & $n=63$ & $n=67$ \\
\hline Baseline & $67.0(37.9-96.1,205)$ & $58.0(35.0-84.0)$ & $63.0(28.0-91.0)$ \\
\hline EOT $^{1}$ & $40.0(0-80.4,205)$ & $38.5(16.0-73.0)$ & $49.0(22.0-80.5)$ \\
\hline Post-tx 4 & $38.0(0-82.9,155)$ & $\mathrm{n} / \mathrm{a}$ & $\mathrm{n} / \mathrm{a}$ \\
\hline Final follow up ${ }^{2}$ & $44.0(0-88.1,133)$ & $42.0(17.0-63.0)$ & $56.0(28.0-77.0)$ \\
\hline Change: final follow-up minus baseline & -23.0 & -16.0 & -7.0 \\
\hline \multicolumn{4}{|l|}{ Hot Flush Rating Scale (HFRS) } \\
\hline \multirow[t]{2}{*}{ HFRS Scores } & \multirow[t]{2}{*}{ NADA (mean SD, $\mathrm{n}$ ) } & CBT (mean SD) & Usual Care (mean SD) \\
\hline & & $n=63$ & $n=67$ \\
\hline Baseline & $7.6(1.7,196)$ & $6.9(1.73)$ & $6.5(2.13)$ \\
\hline $\mathrm{EOT}^{1}$ & $5.4(2.6,196)$ & $4.1(2.01)$ & $5.5(2.61)$ \\
\hline Post-tx 4 & $4.90(2.5,154)$ & $\mathrm{n} / \mathrm{a}$ & $\mathrm{n} / \mathrm{a}$ \\
\hline Final follow up ${ }^{2}$ & $5.2(2.56,135)$ & $3.7(2.16)$ & $5.5(2.45)$ \\
\hline Change: final follow-up minus baseline & -2.4 & -3.2 & -1 \\
\hline \multicolumn{4}{|c|}{${ }^{1}$ EOT is after the 8 th treatment for NADA and 9 weeks after randomisation for CBT study } \\
\hline \multicolumn{4}{|c|}{${ }^{2}$ Final follow up is 18 weeks post EOT for NADA and 26 weeks post randomisation for CBT study } \\
\hline
\end{tabular}

1. Fenlon D, Maishman T, Day L, Nuttall J, May C, Ellis M, Raftery J, Turner L, Fields J, Griffiths G, Hunter MS (2020) Effectiveness of nurse-led group CBT for hot flushes and night sweats in women with breast cancer: results of the MENOS4 randomised controlled trial. Psychooncology. 29: 1514-1523. https://dx.doi.org/10.1002\%2Fpon.5432

\section{Figures}




\section{Paperwork available for 415 referrals to service}

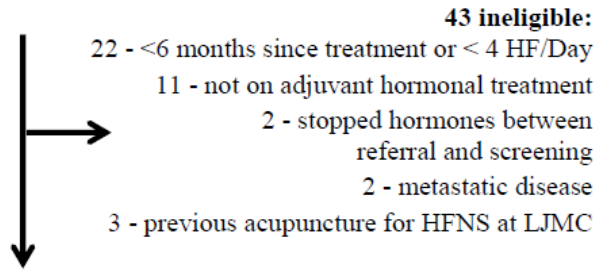

\section{2 eligible}

57 withdrew prior to intake interview: 13 - Travel too far, or able to access local acupuncture service nearer home 7 - returned to work between referral and screening 2 - inconvenient day or time 18 - unable to contact after referral to conduct screening 17 - declined treatment following screening, reason not documented

\section{5 completed intake interview}

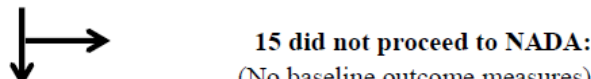

(No baseline outcome measures)

\section{0 had at least one NADA treatment}

275 completed 8 treatments

11 completed 4-7 treatments

12 completed 1-3 treatments

2 number of treatments missing

$\downarrow$

Return of outcome measures

\begin{tabular}{|l|c|c|c|c|}
\hline & $\begin{array}{c}\text { Medical/ } \\
\text { Sociodemographic }\end{array}$ & $\begin{array}{c}\text { Hot Flush } \\
\text { Diary }\end{array}$ & $\begin{array}{c}\text { Hot Flush } \\
\text { Rating Scale } \\
\text { (HFRS) }\end{array}$ & $\begin{array}{c}\text { Women's } \\
\text { Health } \\
\text { Questionnaire } \\
\text { (WHQ) }\end{array}$ \\
\hline Baseline & 293 & 288 & 284 & 284 \\
\hline Baseline \& EOT & $\mathrm{n} / \mathrm{a}$ & 205 & 197 & 202 \\
\hline Baseline \& Post-tx 4 & $\mathrm{n} / \mathrm{a}$ & 165 & 155 & 162 \\
\hline Baseline \& Post tx 18 & $\mathrm{n} / \mathrm{a}$ & 141 & 138 & 133 \\
\hline Complete data set & $\mathrm{n} / \mathrm{a}$ & 117 & 105 & 108 \\
\hline Missing Baseline & 7 & 12 & 16 & 16 \\
\hline
\end{tabular}

Figure 1

Flow diagram showing progress of 415 referrals including eligibility, treatment, and return of outcome measures

\section{Supplementary Files}

This is a list of supplementary files associated with this preprint. Click to download.

- deValoisTIDieRChecklist.docx 